\title{
LIRAGLUTIDE IMPROVES BETA-CELL FUNCTION, MEASURED BY THE C-PEPTIDE/GLUCOSE RATIO, IN OBESE PATIENTS WITH TYPE 2 DIABETES.
}

\author{
AM Ramos-Leví ${ }^{1}$, MA Rubio Herrera ${ }^{2}$
}

${ }^{1}$ Department of Endocrinology and Nutrition, Hospital Universitario de la Princesa, IIP, Universidad Autónoma de Madrid. ${ }^{2}$ Department of Endocrinology and Nutrition, Hospital Clínico San Carlos, IdISSC. SPAIN

\section{INTRODUCTION}

Beta-cell function declines progressively in patients with type 2 diabetes (T2D). the fasting C-peptide/glucose ratio $(\mathrm{Cp} / \mathrm{G})$ is used for its evaluation. The GLP-1 receptor agonist liraglutide improves glucose and weight control, presumably due to improvement of beta-cell function and/or mass. This study evaluates the effect of a 6-months' treatment with liraglutide in beta-cell function, measured by $\mathrm{Cp} / \mathrm{G}$, in patients with obesity and T2D.

\section{PATIENTS AND METHODS}

We performed an observational retrospective and prospective analysis of a cohort of 43 patients ( 24 women) with orally-treated T2D and obesity, to whom liraglutide $1.2 \mathrm{mg} /$ day was added. At 3 months, dosage of liraglutide was increased to $1.8 \mathrm{mg} /$ day in those cases in which $\mathrm{HbA1c}$ or weight goals were not fully achieved. We evaluated clinical and analytical data before and after 6 months of treatment. Statistical analysis with IBM SPSS Statistics Inc., version 21.0, using $\mathrm{Cp} / \mathrm{G}$ as a surrogate marker of beta-cell function.

\section{RESULTS}

Patients' basal characteristics prior to initiating liraglutide are shown in table 1. Mean T2D duration was $6.7 \pm 3.8$ years. Twenty six (60.5\%) patients previously received one oral hypoglycemic agent (OHA) (metformin), and the rest of them were on two OHA. At 3 months, dosage was increased to 1.8 $\mathrm{mg} /$ day in $24(55.8 \%)$ cases; these patients had higher pre-treatment $\mathrm{HbA} 1 \mathrm{c}$ levels $(7.8 \pm 0.9$ vs $7.3 \pm 0.7 \%, p=0.025)$ and lower $\mathrm{Cp} / \mathrm{G}$ values $(0.0235 \pm$ 0.0099 vs $0.0295 \pm 0.0101, p=0.057)$, in comparison to those who remained on $1.2 \mathrm{mg} /$ day.

After 6 months of liraglutide, percentage weight loss (\%WL) was $5.2 \pm 4.8 \mathrm{~kg}$. BMI, FG, HOMA and HbA1c were significantly decreased (table 1). Mean $\mathrm{HbA} 1 \mathrm{c}$ reduction was $-0.79 \pm 0,92 \%$ (which meant a reduction of $10.6 \pm$ 11.5\%). cP/G values at 6 months increased $15.4 \pm 36.6 \%$, reaching $0.0296 \pm$ 0.0148 . Amelioration occurred regardless of pretreatment $\mathrm{HbA1c}$ or final dose of liraglutide.

Basal $\mathrm{CP} / \mathrm{G}$ values correlated with \%WL and HbA1c at 6 months (figure 1). Decrease of $\mathrm{HbA} 1 \mathrm{c}$ levels and \%WL were similar regardless of pre-treatment $\mathrm{HbA1c}, \mathrm{BMI}$ or $\mathrm{Cp} / \mathrm{G}$ (figures 2-4).

Patients who were previously on only one OHA showed higher $\mathrm{Cp} / \mathrm{G}$ at 6 months $(0.0341$ vs $0.0226, p<0.05)$ (figure 5$)$. Individuals with pre-treatment $\mathrm{Cp} / \mathrm{G}$ within the lower quartile achieved 6-month HbA1c levels $<7 \%$ less frequently (figure 6). Patients to whom liraglutide was increased to 1.8 $\mathrm{mg} /$ day achieved lower \%WL (7.1 \pm 5.7 vs $3.6 \pm 3.1, \mathrm{p}=0.013)$ (figure 7$)$, but there were no differences in the variation of $\mathrm{HbA} 1 \mathrm{c}$ or $\mathrm{Cp} / \mathrm{G}$ values.

$\begin{array}{ccc}\begin{array}{c}\text { Pre-liraglutide } \\ \text { (mean } \pm \text { SD) }\end{array} & \begin{array}{c}6 \text { months after liraglutide } \\ \text { (mean } \pm \text { SD) }\end{array} & p \\ 39.3 \pm 4.9 & 37.3 \pm 5.2 & 0.000 \\ 149.8 \pm 36.9 & 132.5 \pm 47.3 & 0.006 \\ 7.6 \pm 0.8 & 6.8 \pm 1.2 & 0.000 \\ 6.1 \pm 3.3 & 4.8 \pm 3.2 & 0.019 \\ 0.0261 \pm 0.0103 & 0.0296 \pm 0.0148 & 0.047\end{array}$

$\mathrm{MI}\left(\mathrm{kg} / \mathrm{m}^{2}\right)$

Fasting glucose $(\mathrm{mg} / \mathrm{dL})$

MA-IR

-peptide/glucose

$0.0261 \pm 0.0103$

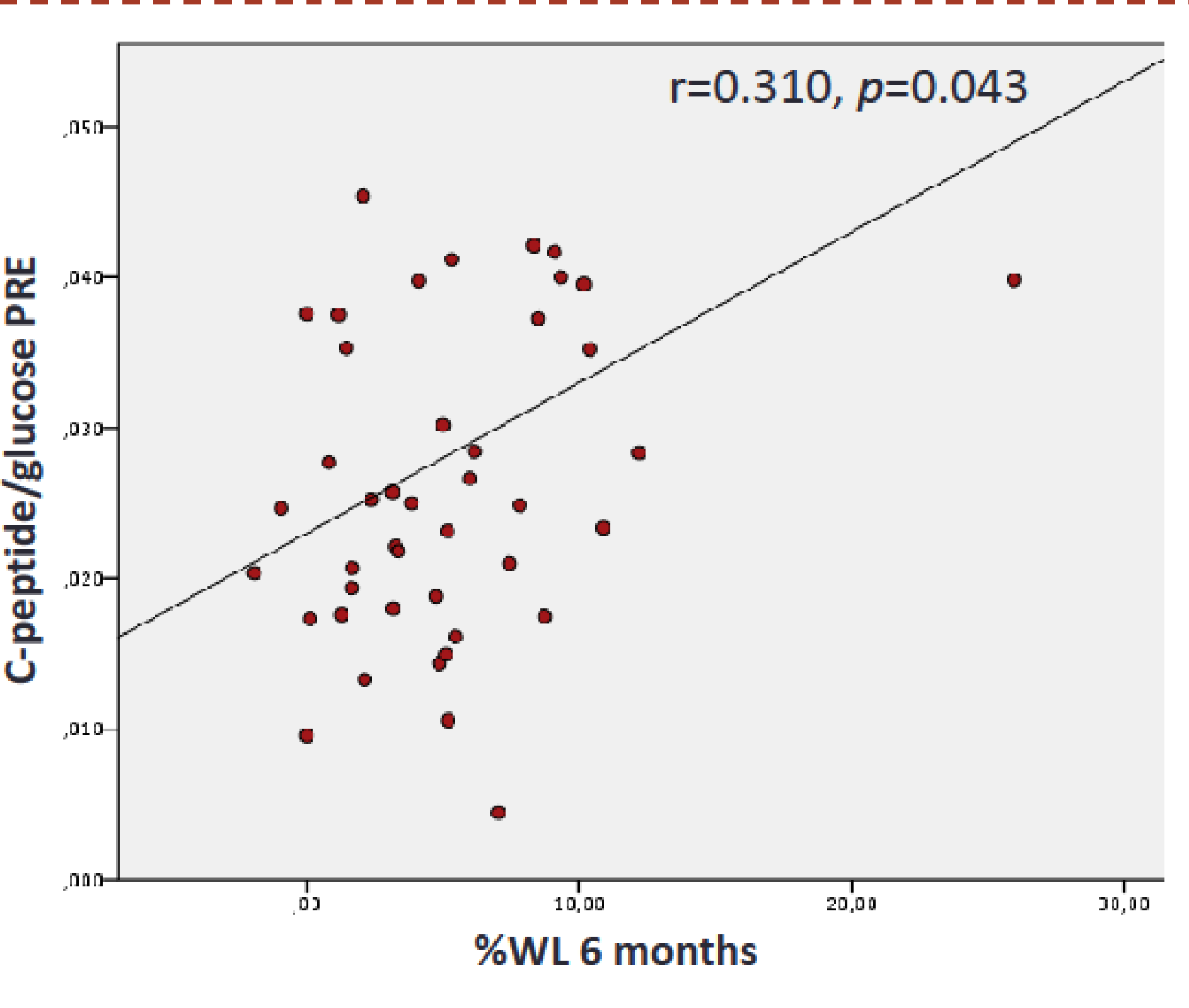

Figure 1. Bivariate correlations (Pearson)

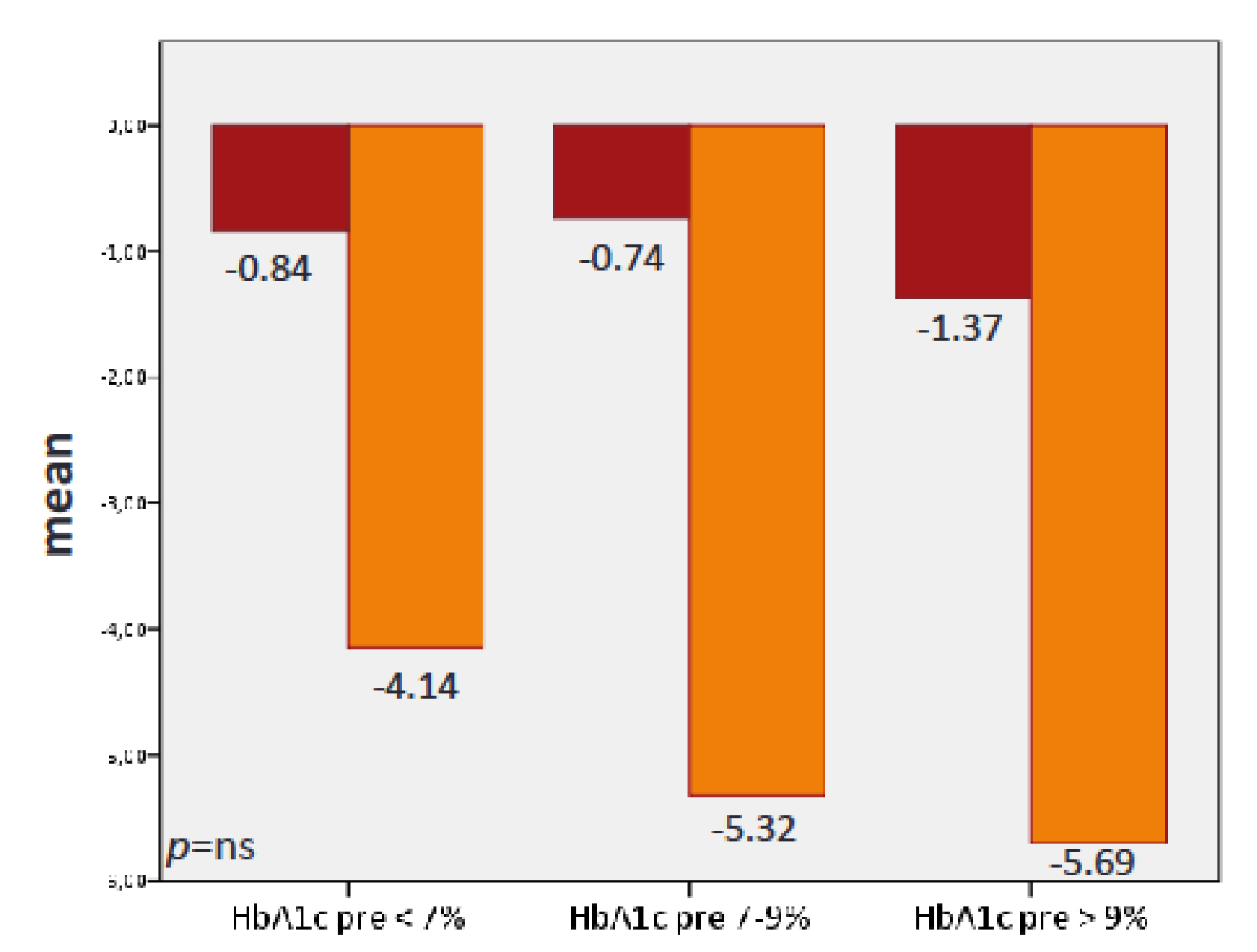

Figure 2. HbA1c reduction (simple difference) and \%WL $\square$, according to pre-treatment $\mathrm{HbA} 1 \mathrm{c}$

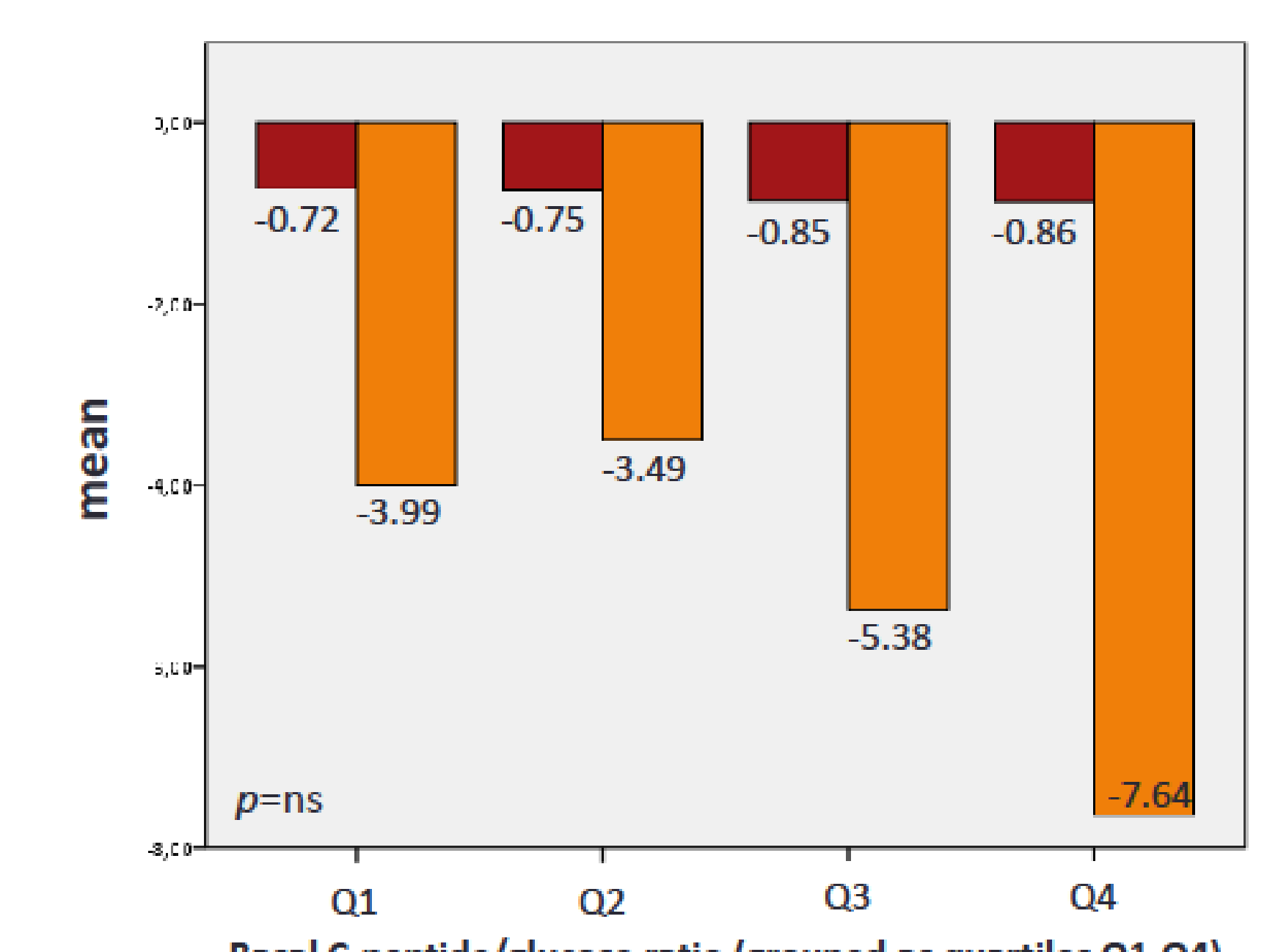

igure 4. HbA1c reduction (simple difference) and $\% \mathrm{WL}-$, according to pre-treatment Cpeptide/glucose ratio, grouped as quartiles.
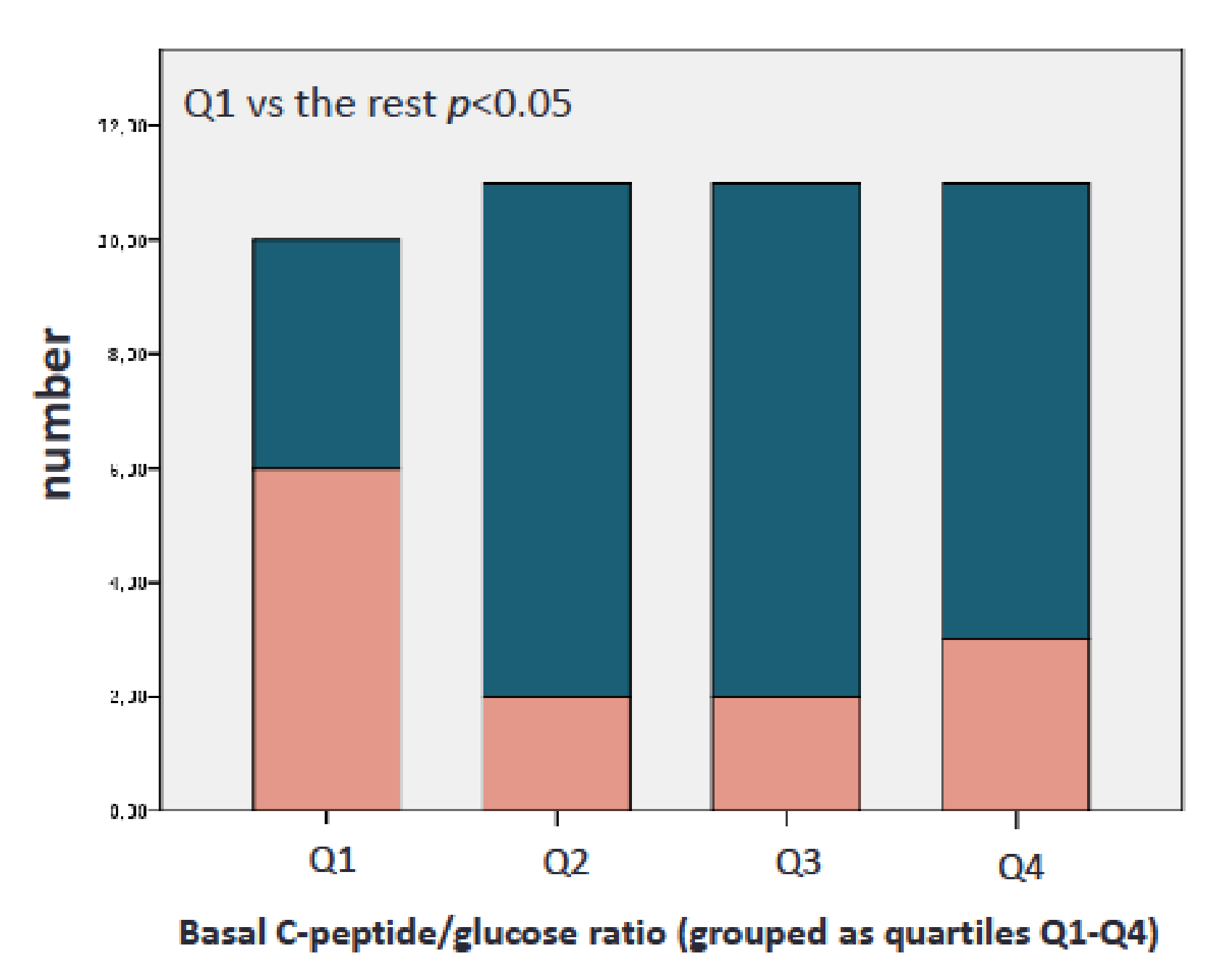

Figure 6. Number of patients with $\mathrm{HbA1c}$ values at 6 months $<7 \%$ and $>7 \% \square$, according to pre-treatment
as quartiles.
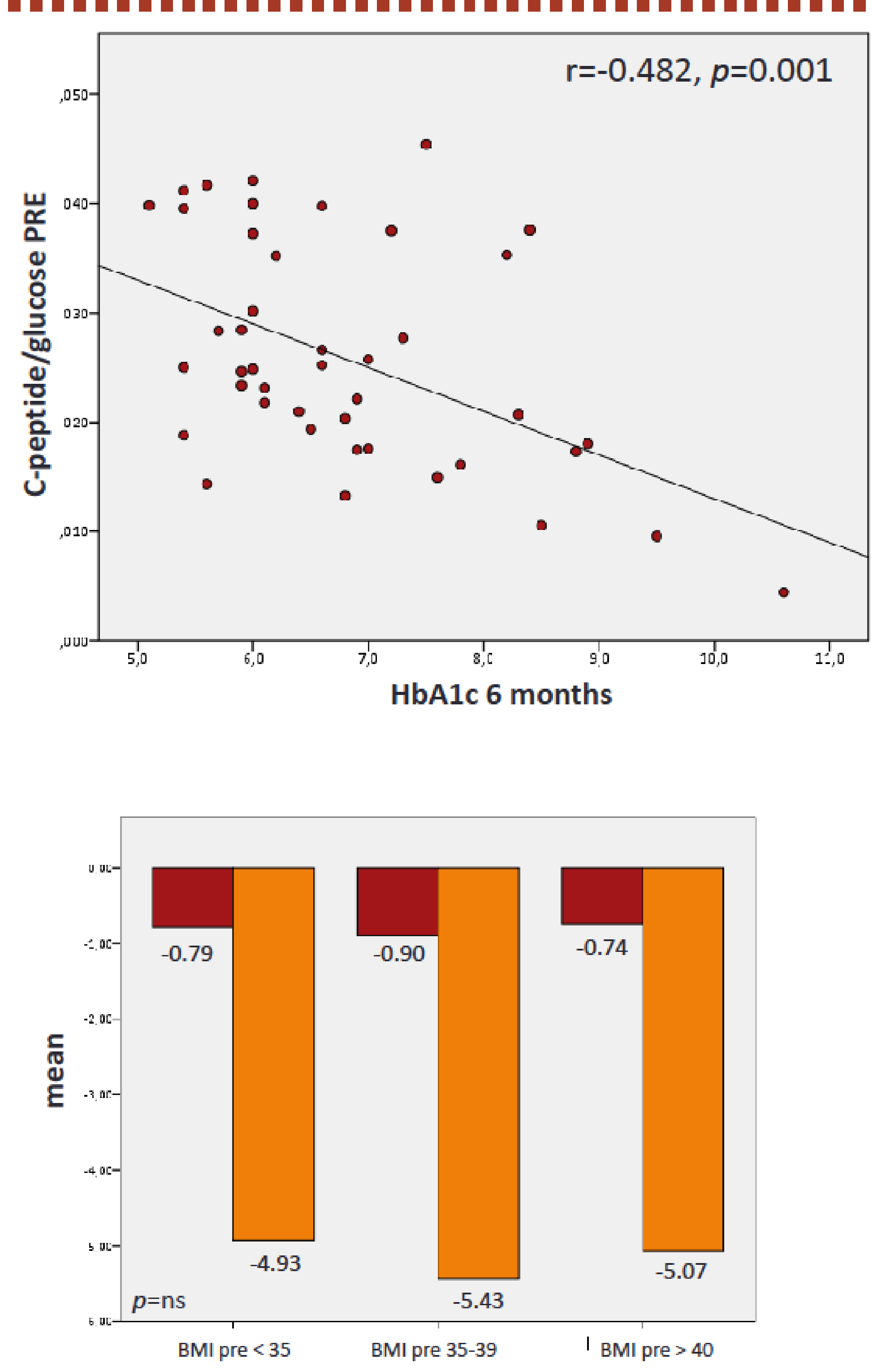

Figure 3. HbA1c reduction (simple difference) and $\% \mathrm{WL} \square$, according to pre-treatment BMI

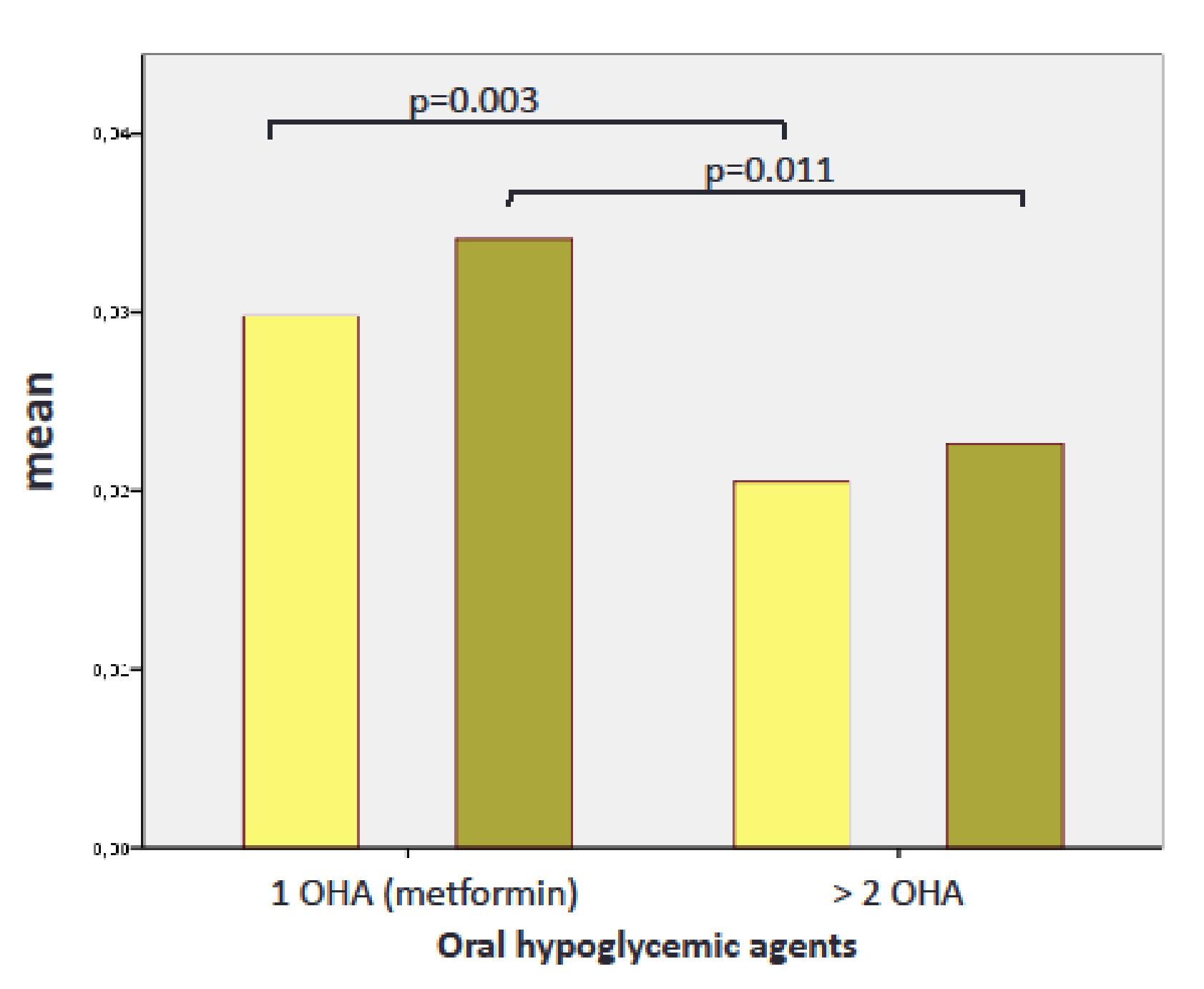

Figure 5. C-peptide/glucose ratio before $₫$ and after 6 months of liraglutide $\square$, according to previous hypoglycemic treatment with oral agents.

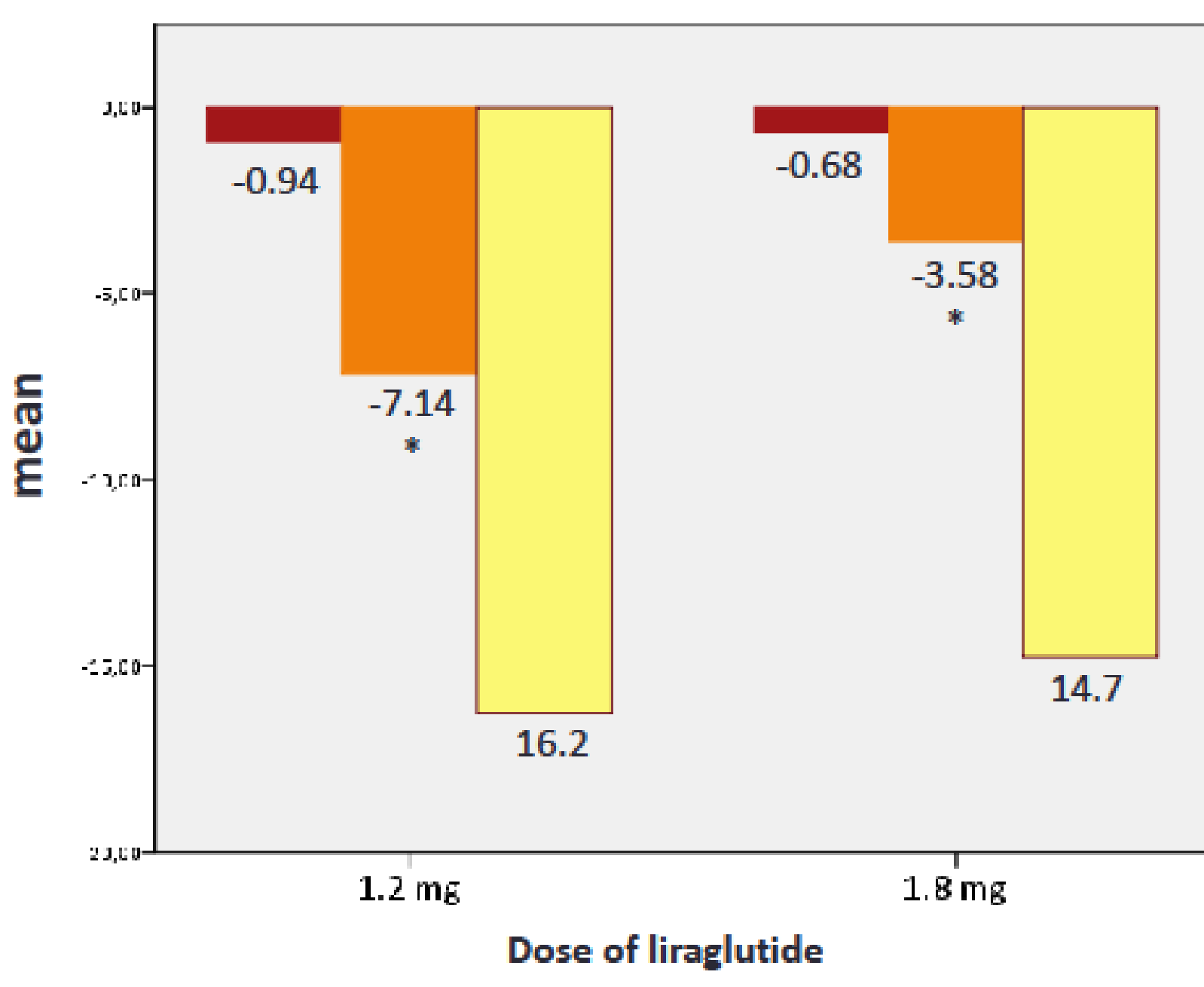

Figure 7. HbA1c reduction $\square, \% W L \square$ and

porcentual difference in C-peptide/glucose ratio according to liraglutide dose

\section{CONCLUSIONS}

Liraglutide seems to improve beta-cell function, measured by $\mathrm{Cp} / \mathrm{G}$, after 6 months, regardless of pre-treatment BMI, HbA1c or Cp/G. A lower basal pre-treatment $\mathrm{Cp} / \mathrm{G}$ is associated to lower rates of optimal glucose metabolism control after 6 months of treatment with GLP-1 agonists. 